\title{
Lateral Suboccipital Approach in Semisitting Position for Resection of Vagal Schwannoma: 2-Dimensional Operative Video
}

\author{
Stefan Lieber ${ }^{1,2}$ Maximiliano Nunez ${ }^{2}$ Marcos Tatagiba ${ }^{1}$ \\ ${ }^{1}$ Department of Neurological Surgery, Eberhard-Karls-University, \\ University Hospital Tübingen, Germany \\ 2 Department of Neurological Surgery, Microsurgical Neuroanatomy \\ Address for correspondence Stefan Lieber, MD, Department of \\ Neurological Surgery, Eberhard-Karls-University, \\ Hoppe-Seyler-Strasse 3, D-72076 Tübingen, Germany \\ Laboratory, University of Pittsburgh, Pennsylvania, United States \\ (e-mail: Stefan.Lieber@uclmail.net).
}

J Neurol Surg B 2021;82(suppl S1):S51-S52.

\begin{abstract}
Keywords

- Vagal Schwannoma

- vagal neurinoma

- jugular foramen

- lateral suboccipital approach

- operative video

- semisitting position

We present a case of a sizeable vagal schwannoma that was resected through a lateral suboccipital approach in semisitting position. An extra-axial lesion, occupying the left cerebellomedullary cistern and extending from the pontomedullary junction to the jugular foramen was incidentally discovered in a 40-year-old woman afflicted with secondary progressive multiple sclerosis during repeated magnetic resonance imaging (-Fig. 1). On physical examination, a mild deviation of the uvula to the right and a diminished gag reflex were observed. The patient was referred to our department after considerable growth of the lesion was noted and a broad interdisciplinary consensus was reached to treat the lesion surgically.

A gross total resection was achieved, histopathology confirmed a WHO I schwannoma with a low proliferation index. Postoperative dysphonia resolved completely within a few weeks, there was no collateral neurological deficit and especially no functional dysphagia. At 3-year follow-up, there was no indication of residual or recurrence.

This 2-dimensional video demonstrates pre- and postoperative imaging, positioning and set-up of operating room, anatomical and surgical nuances of the skull base approach, and the operative technique for microdissection of the schwannoma from the critical neurovascular structures (- Fig. 2).

In summary, the lateral suboccipital approach in semisitting position is a powerful tool in the armamentarium for the microsurgical management of various pathologies residing in the posterior cranial fossa, especially large and vascularized schwannomas. Provided the necessary anesthesiological precautions and intraoperative procedures the semisitting position is safe and effective.

The link to the video can be found at: https://youtu.be/-9o_qJGkQhg.
\end{abstract}

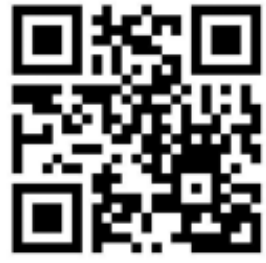

received

May 9, 2019 accepted after revision January 4, 2020 published online September 17, 2020

Conflict of Interest

None declared.

www.thieme.com/skullbasevideos

www.thieme.com/jnlsbvideos

DOI https://doi.org/ 10.1055/s-0040-1701656. ISSN 2193-6331. (c) 2020. The Author(s).

This is an open access article published by Thieme under the terms of the Creative Commons Attribution-NonDerivative-NonCommercial-License, permitting copying and reproduction so long as the original work is given appropriate credit. Contents may not be used for commercial purposes, or adapted, remixed, transformed or built upon. (https://creativecommons.org/ licenses/by-nc-nd/4.0/)

Georg Thieme Verlag KG, Rüdigerstraße 14, 70469 Stuttgart, Germany 


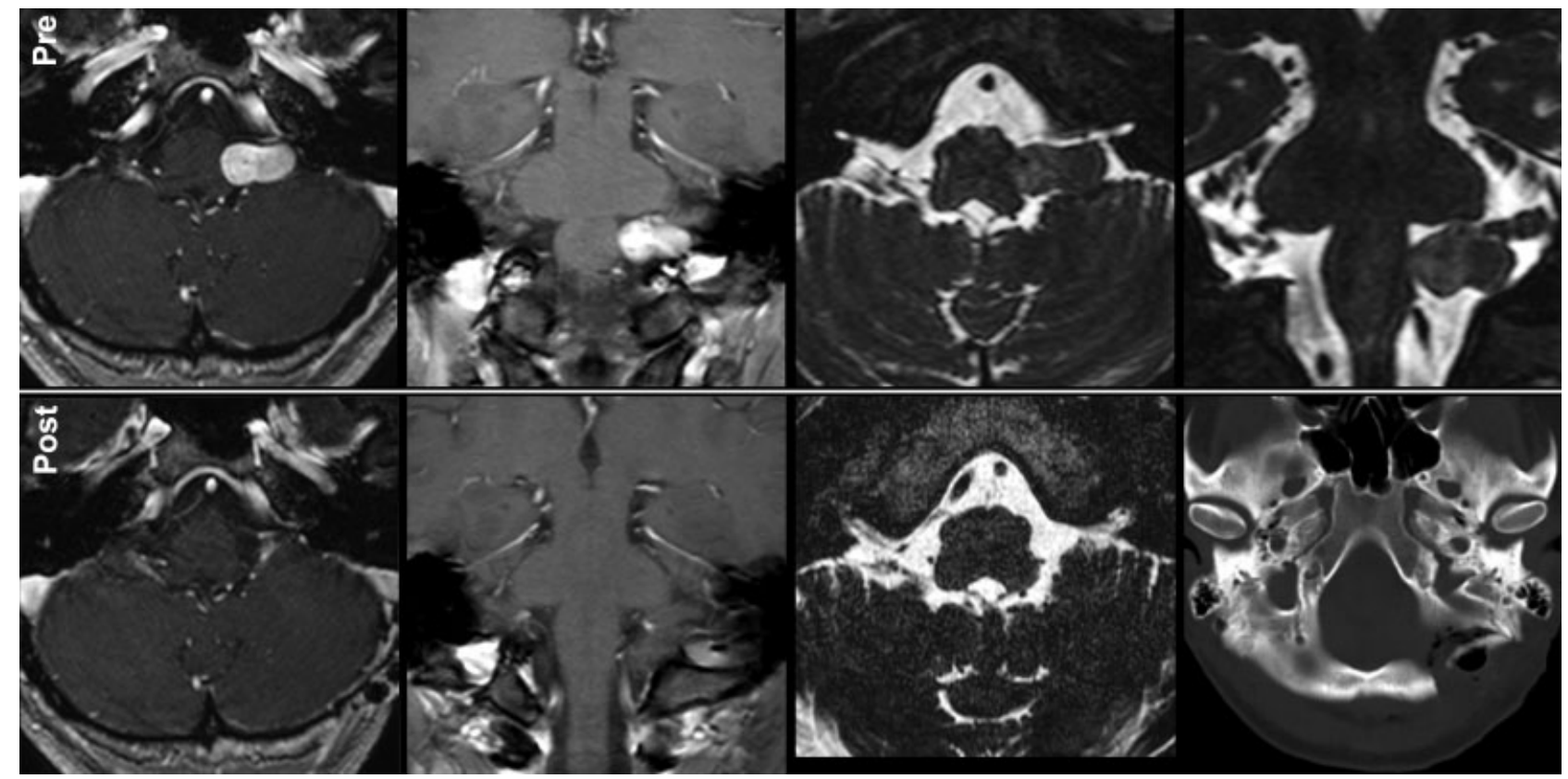

Fig. 1 Pre- and postoperative MRI and CT studies of the left-sided vagal schwannoma. CT, computed tomography; MRI, magnetic resonance imaging.

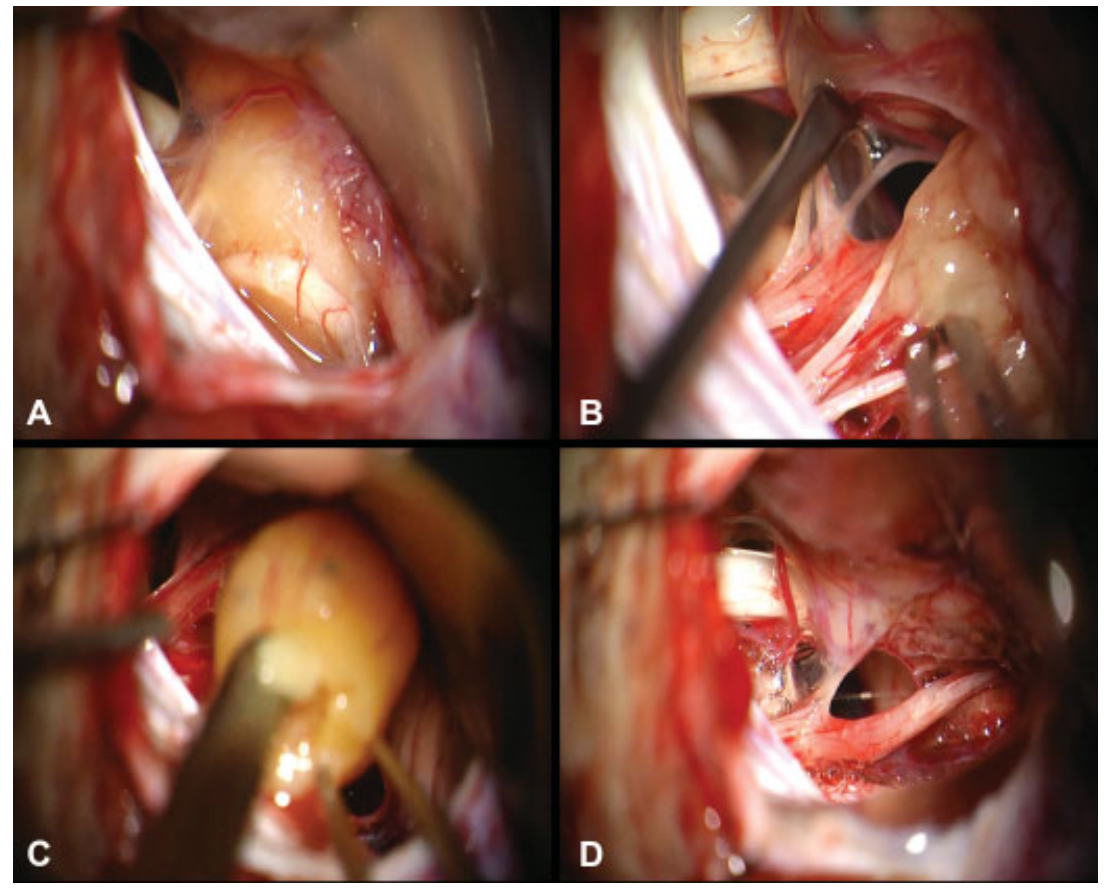

Fig. 2 Operative still images of a left-sided lateral suboccipital approach: (A) exposure of the schwannoma in the cerebellomedullary cistern, some vagal nerve fascicles are ensheathed by and blend into the tumor, (B) the schwannoma is dissected off of nerve fascicles, (C) en bloc resection of the residual tumor with its capsule, (D) after complete microsurgical excision of the vagal schwannoma. 